\title{
ВЛИЯНИЕ РЕЖИМОВ ОБЛУЧЕНИЯ МИШЕНЕЙ ИЗ ГИДРОКСИАПАТИТА МОЩНЫМИ ИМПУЛЬСНЫМИ ИОННЫМИ ПУЧКАМИ НА СВОЙСТВА СФОРМИРОВАННЫХ КАЛЬЦИЙ-ФОСФАТНЫХ ПОКРЫТИЙ
}

\author{
(C) 2013 г. Г. А. Блейхер, Т. Л. Волокитина, С. И. Твердохлебов \\ Томский политехнический университет, Томск, Россия \\ Поступила в редакцию 01.02.2013 г.
}

\begin{abstract}
Исследованы физико-механические свойства биосовместимых кальций-фосфатных покрытий, осажденных на титановые и кремниевые подложки из эрозионного материала, образованного при облучении мишеней из гидроксиапатита (синтетического и натурального) мощным импульсным ионным пучком ускорителя ТЕМП-4М. Предложена расчетная методика для прогнозирования скорости и энергоэффективности осаждения по заданным параметрам импульсных ионных пучков. Выполнен анализ этих характеристик применительно к формированию кальций-фосфатных покрытий.
\end{abstract}

\section{ВВЕДЕНИЕ}

Многочисленные исследования надежно доказывают способность мощных импульсных ионных пучков (МИИП) с энергией частиц 100-1000 кэВ и плотностью мощности $10^{7}-10^{9} \mathrm{BT} / \mathrm{cm}^{2}$ интенсивно удалять вещество с облучаемой поверхности и быть инструментом для осаждения модифицирующих покрытий различного состава и назначения. Опубликованные экспериментальные результаты свидетельствуют о том, что технологии на основе современных МИИП обладают рядом привлекательных свойств. В частности, они позволяют сохранять стехиометрический состав вещества мишени в осаждаемых покрытиях, обеспечивают их чистоту. При этом достигается довольно большая площадь обработки (десятки квадратных сантиметров) и приемлемая производительность [1-3]. МИИП могут применяться и для осаждения биосовместимых кальций-фосфатных покрытий (КФ-покрытий) на поверхность различных имплантатов, использующихся в стоматологии, травматологии и ортопедии [4-6]. Основа этих изделий чаще всего изготавливается из титана, его сплавов или коррозионноустойчивой высококачественной стали, а КФ-покрытия способствуют процессу остеогенеза костной ткани, фиксации имплантата за счет срастания материала покрытия и кости.

Одна из важных задач в создании надежных и эффективных технологий формирования КФ-покрытий с применением МИИП состоит в том, чтобы добиться баланса между производительностью и качеством формируемых покрытий. Необ- ходимо научиться выявлять параметры МИИП, при которых сформированные покрытия не только удовлетворяли бы биомедицинским требованиям, но и обеспечивали бы наиболее высокие показатели производительности и энергоэффективности основных технологических процессов.

Выполненные исследования свойств КФ-покрытий, осажденных с использованием субмикросекундных ионных пучков, показали, что эти покрытия способны удовлетворять требованиям, предъявляемым к медицинским изделиям. Было подтверждено, что они нетоксичны, апирогенны, не вызывают дегенеративных изменений тканей при имплантации, соответствуют требованиям нормативных документов. Однако скорость их осаждения довольно низкая (не более нескольких нанометров за один импульс тока пучка [4-7]). Также нет ясности в вопросе о том, являются ли используемые в экспериментах режимы работы ускорителей оптимальными с точки зрения энергоэффективности получения осаждаемого материала.

Эффективность пучково-плазменных технологий осаждения покрытий во многом определяется интенсивностью и энергоэффективностью удаления вещества с поверхности облучаемой мишени. В этом отношении использование МИИП имеет преимущество перед многими другими известными методами. Так, коэффициенты эрозии поверхности твердого тела, вызванной испарением под действием МИИП с начальной энергией частиц $E_{0}=10-1000$ кэВ и плотностью мощности $P=10^{7}-10^{9} \mathrm{~B}$ T $/ \mathrm{cm}^{2}$, на три-четыре порядка выше 


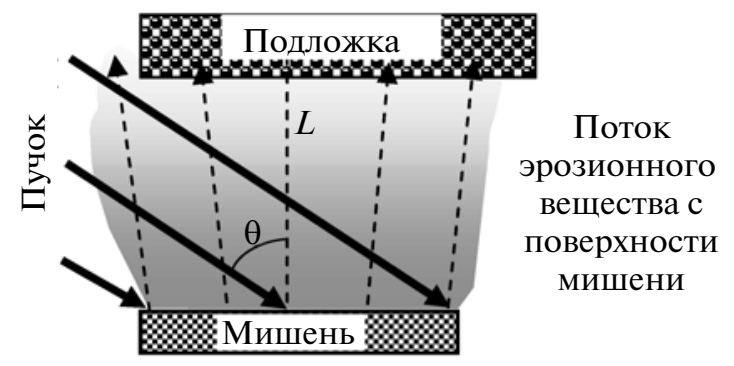

Рис. 1. Схема осаждения покрытий из эрозионного материала, извлекаемого из поверхностных слоев мишени под действием мощных импульсных ионных пучков.

коэффициентов распыления, создаваемого непрерывными слаботочными ионными пучками или под действием плазмы магнетронного разряда $[8,9]$. КПД субмикросекундных ионных ускорителей составляет 20-40\%, что значительно выше КПД импульсных лазерных источников [5, 10]. При этом ионные пучки с энергией частиц выше 10 кэВ практически не отражаются от поверхности мишени, в отличие от лазерного излучения.

Настоящая статья посвящена анализу свойств КФ-покрытий, сформированных в результате осаждения эрозионного материала, создаваемого в результате облучения мишеней из гидроксиапатита (синтетического и натурального) мощными ионными пучками субмикросекундной длительности на современном ускорителе ТЕМП-4М [10]. Для исследования производительности и энергоэффективности осаждения были привлечены численные модели эрозии поверхности твердого тела под действием мощных импульсных пучков заряженных частиц $[8,9]$. Их применение к решению данной задачи предоставляет возможность расчетным путем прогнозировать производительность осаждения и помогает выявлять оптимальные параметры облучения.

\section{МЕТОДИКА ЭКСПЕРИМЕНТА}

Принципиальная схема осаждения покрытий при использовании МИИП изображена на рис. 1. Высокоэнергетические частицы ионного пучка бомбардируют поверхность твердотельной мишени под углом $\theta$ к ее нормали. В результате их торможения из поверхностных слоев мишени эмитируют частицы (атомы, молекулы и др.). Их поток принято называть абляционным или эрозионным. Он распространяется в окружающее пространство и осаждается на подложке, расположенной параллельно к поверхности мишени или под небольшим углом к ней на некотором расстоянии $L$. Весь процесс происходит в условиях высокого вакуума (давление в камере $10^{-4}-10^{-2}$ Па).
В настоящей работе были использованы две мишени $\left(\mathrm{Ca}_{10}\left(\mathrm{PO}_{4}\right)_{6}(\mathrm{OH})_{2}\right)$, изготовленные из гидроксиапатита (ГАП) разной природы и при разных режимах отжига. Одна из мишеней была спрессована из порошка синтетического ГАП, полученного механохимическим методом по керамической технологии [11] с добавлением кремния. Отжиг полученной заготовки осуществлялся на воздухе при температуре $1100^{\circ} \mathrm{C}$. В дальнейшем эту мишень будем называть синтетической. Для изготовления другой мишени, которую будем называть натуральной, использовался порошок натурального ГАП с отжигом полученной заготовки на воздухе при температуре $950^{\circ} \mathrm{C}$.

Ионный пучок субмикросекундного ускорителя ТЕМП-4М, под действием которого на поверхности мишени создавался эрозионный поток, имел следующие параметры [10]: ускоряющее напряжение 200-250 кВ; длительность импульса тока пучка, состоящего из $70 \% \mathrm{C}^{+}$и $30 \% \mathrm{H}^{+}$, равнялась примерно 80 нс; плотность тока на мишени 150-200 A/см²; радиус следа пучка на поверхности мишени - около 2.5 см; угол падения пучка на мишень $(\theta)$ составлял примерно $45^{\circ}$ (рис. 1 ); расстояние $L$ между поверхностями мишеней и подложек было 6-7 см. Формирование покрытий происходило в результате серии импульсов, частота следования которых составляла $0.1-1.0$ Гц.

Эрозионный поток осаждался на подложки из титана и кремния. Предварительно поверхность титановых подложек была механически отполирована с применением пасты ГОИ. Для улучшения адгезионных свойств покрытий в ходе эксперимента подложки нагревались до $350^{\circ} \mathrm{C}$.

Определение элементного состава покрытий, осажденных на титановые подложки, проводилось на оже-спектрометре Шхуна-2 и с использованием растрового электронного микроскопа Philips SEM 515, имеющего встроенную приставку для энергодисперсионного рентгеновского анализа. Спектры энергодисперсионного анализа (ЭДС-спектры) позволяют оценивать соотношение различных элементов в покрытии. Физикомеханические свойства осажденных покрытий изучались методом наноиндентирования на приборе НаноСкан. Измерение толщины КФ-покрытий проводилось на профилометре-профилографе TALYSURF 5 с использованием подложек из полированного кремния. Токсикологические испытания были проведены в аккредитованном испытательном лабораторном центре Новосибирский НИИ гигиены.

\section{ЭКСПЕРИМЕНТАЛЬНЫЕ РЕЗУЛЬТАТЫ И ИХ ОБСУЖДЕНИЕ}

Оже-спектры покрытий, полученных при использовании синтетической и натуральной ми- 

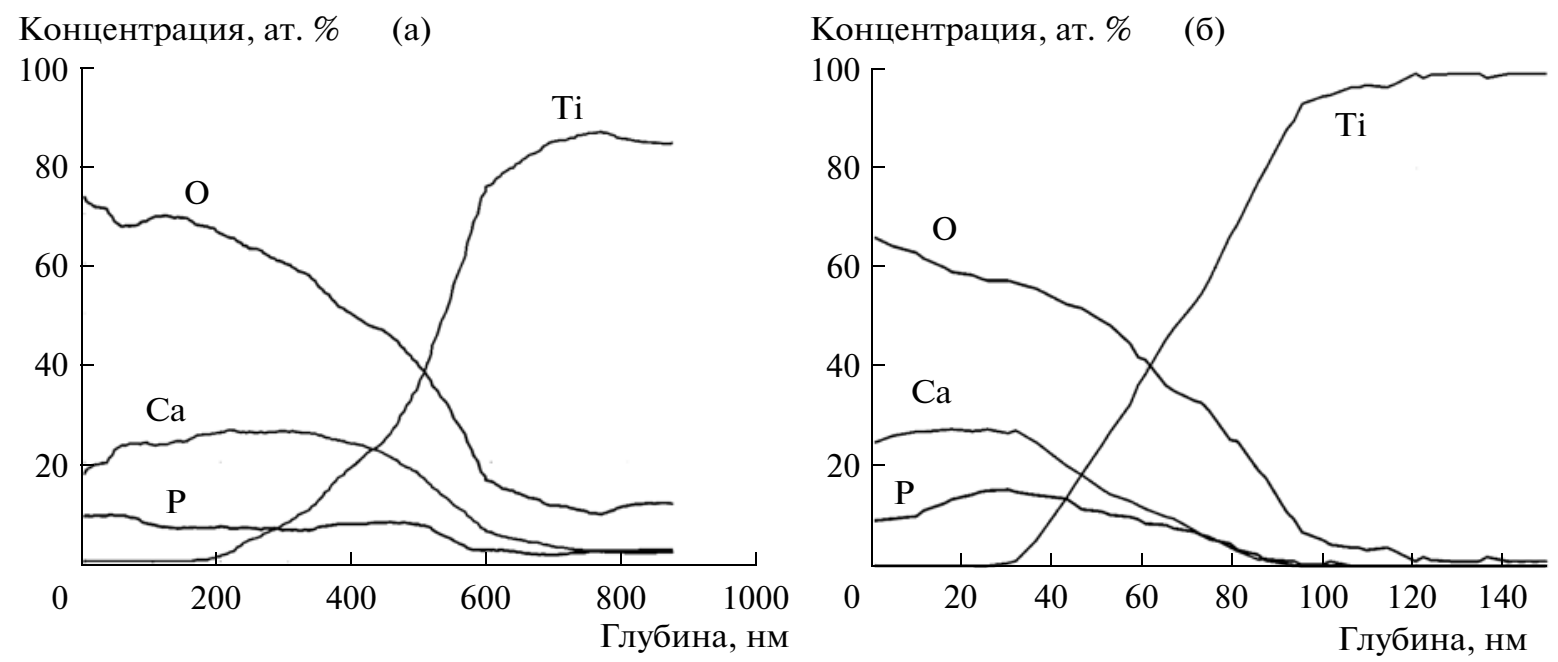

Рис. 2. Оже-спектры КФ-покрытий, осажденных на титановую подложку в результате облучения натуральной (а) и синтетической (б) мишеней ионным пучком ускорителя ТЕМП-4М (300 импульсов тока в обоих случаях).

шеней в результате действия 300 импульсов МИИП, приведены на рис. 2. В покрытиях присутствуют основные элементы гидроксиапатитной мишени и титановой подложки: $\mathrm{Ca}, \mathrm{P}, \mathrm{O}, \mathrm{Ti}$. На поверхности покрытия не наблюдаются посторонние примеси и материал основы (титан). Под поверхностью на определенной глубине происходит перемешивание материала покрытия с титаном. Оже-спектры позволяют сделать вывод о том, что покрытие полностью закрывает подложку и имеет хорошую адгезию к ней. Эти свойства являются необходимыми для покрытий имплантатов, так как в этом случае исключается контакт живых тканей организма с материалом основы. На рис. 2 видно, что покрытие, осажденное при использовании натуральной мишени, примерно на порядок толще, чем при использовании синтетической, чем и обуславливается различная глубина перемешивания элементов покрытия и подложки.

Соотношения различных элементов в покрытиях, полученные из энергодисперсионного анализа, представлены в табл. 1. С целью уменьшения влияния материала подложки на спектры анализ осуществлялся при пониженном напряжении 10 кВ. Так как КФ-покрытия являются диэлектриками, то перед анализом на их поверхность наносился проводящий углеродный слой толщиной 5 нм. Поэтому в ЭДС-спектрах покрытий присутствует углерод. Отношение $\mathrm{Ca} / \mathrm{P}$ для синтетической мишени примерно равно 1.24, а для натуральной - 1.13. Это несколько меньше стехиометрического отношения Са/Р в ГАП, которое составляет 1.67. В других экспериментах по осаждению КФпокрытий с использованием МИИП получались значения отношения $\mathrm{Ca} / \mathrm{P}$, более близкие к стехиометрическому [4, 5], что может быть обусловлено различием параметров МИИП и мишеней.
Результаты растровой электронной микроскопии (РЭМ) по исследованию морфологии поверхности КФ-покрытий, осажденных на плоские титановые подложки серией из 300 импульсов, приведены на рис. 3. КФ-покрытия, полученные с использованием синтетической мишени, оказались более тонкими (рис. 3б). Они повторяют морфологию исходной титановой подложки (рис. 3а). На них присутствуют вкрапления, представляющие, по-видимому, капли материала мишени. Покрытия, полученные с использованием мишени из натурального ГАП, имеют более развитую поверхность (рис. 3в). Они полностью покрывают подложку, закрывают исходные царапины, образованные при полировке образцов.

Результаты измерений физико-механических свойств (параметров шероховатости, микротвердости, модуля Юнга) представлены в табл. 2. КФпокрытия увеличивают шероховатость исходной подложки и, соответственно, площадь контакта биотканей с имплантатом, необходимую для остеосинтеза и улучшения прочности их соедине-

Таблица 1. Соотношение различных элементов в КФпокрытиях

\begin{tabular}{c|c|r|r|r}
\hline \multirow{2}{*}{ Элемент } & \multicolumn{2}{|c|}{$\begin{array}{c}\text { Мишень } \\
\text { из синтетического } \\
\text { гидроксиапатита }\end{array}$} & \multicolumn{2}{c}{$\begin{array}{c}\text { Мишень } \\
\text { из натурального } \\
\text { гидроксиапатита }\end{array}$} \\
\cline { 2 - 5 } & мас. \% & ат. \% & мас. \% & ат. \% \\
\hline $\mathrm{C}$ & 12.41 & 25.24 & 14.90 & 28.79 \\
$\mathrm{O}$ & 27.85 & 42.54 & 28.97 & 42.02 \\
$\mathrm{P}$ & 4.35 & 3.43 & 5.39 & 4.04 \\
$\mathrm{Ca}$ & 5.41 & 3.30 & 6.09 & 3.52 \\
$\mathrm{Ti}$ & 49.97 & 25.49 & 44.65 & 21.63 \\
\hline
\end{tabular}




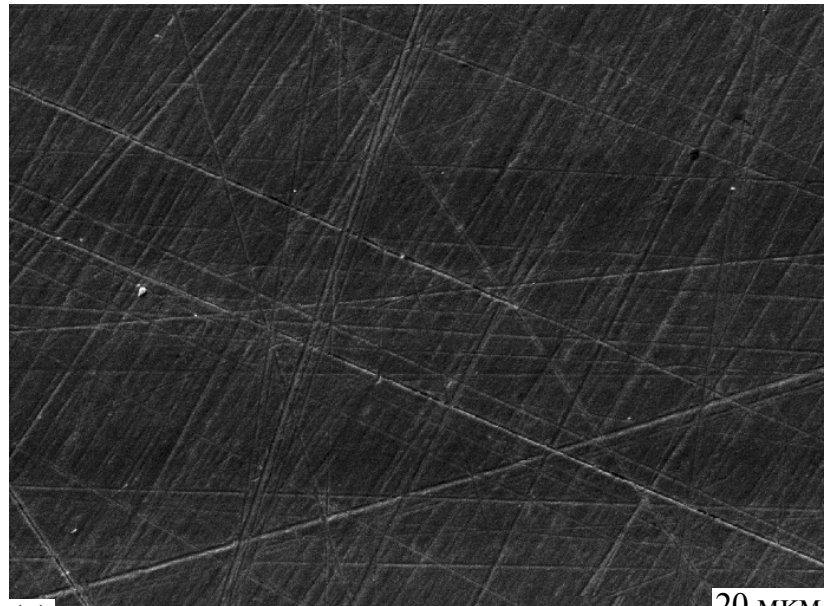

(a)

20 MKM
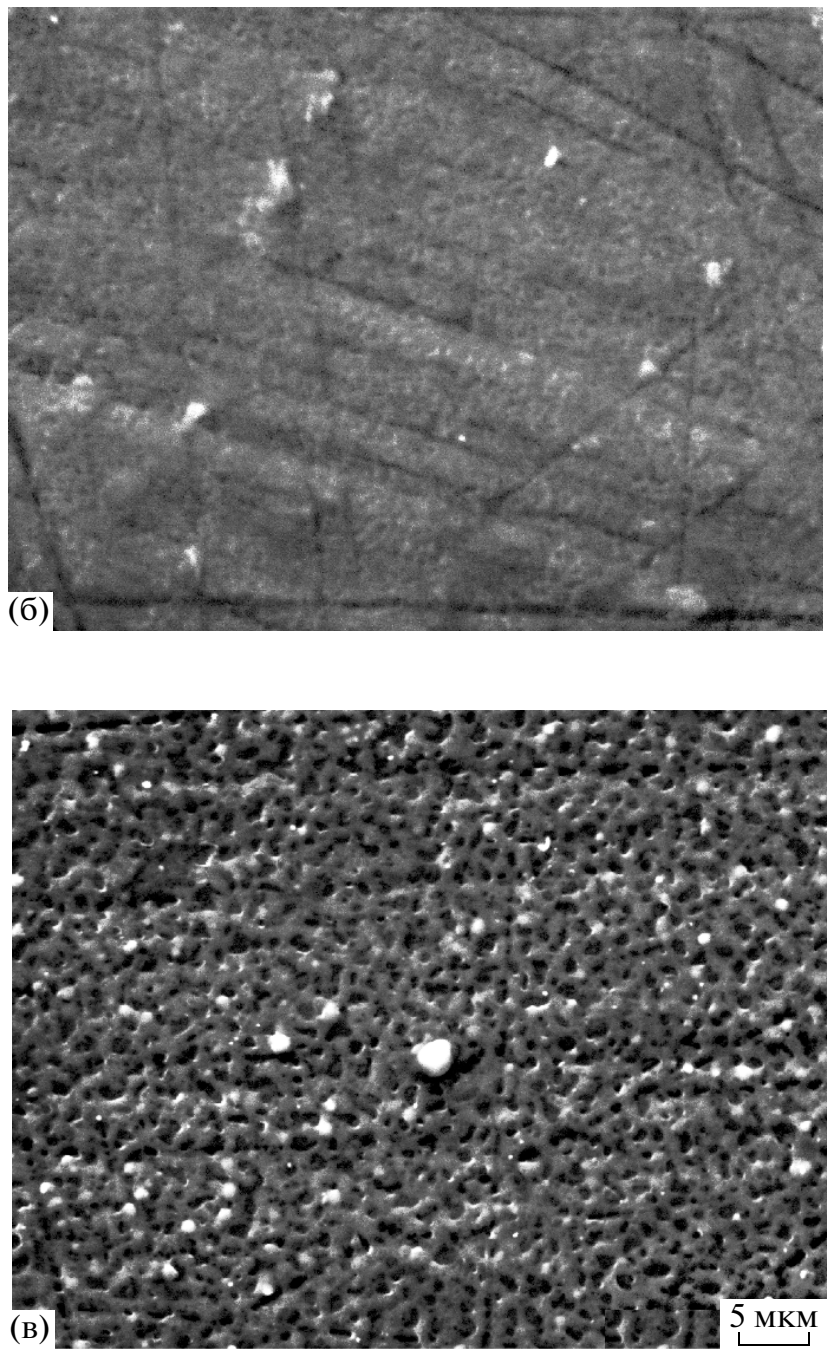

Рис. 3. РЭМ-изображения поверхности титановой подложки без покрытия (а), КФ-покрытий на титановой подложке, полученных при облучении синтетической (б) и натуральной (в) мишеней (300 импульсов тока на ускорителе ТЕМП-4М).

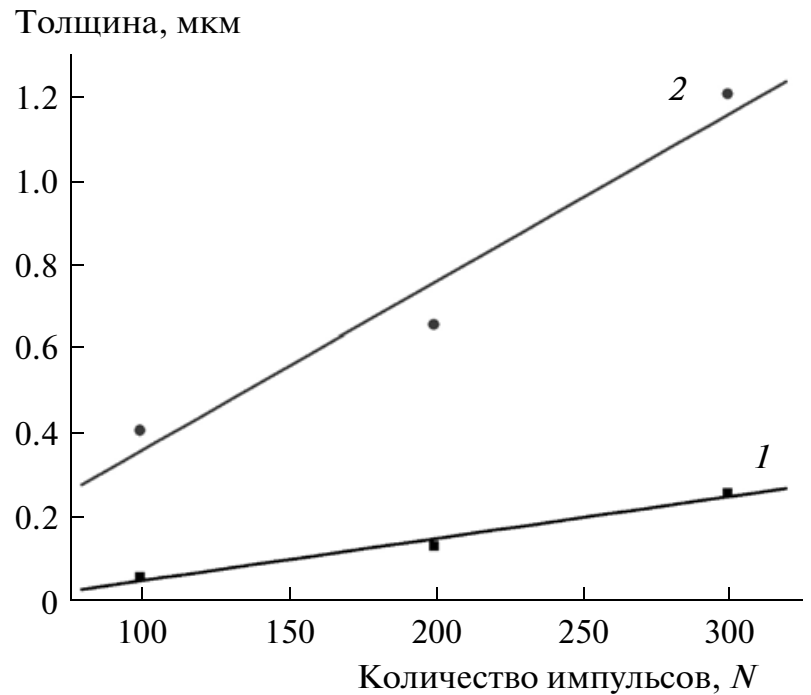

Рис. 4. Зависимость толщины КФ-покрытия от количества импульсов тока ионного пучка ускорителя ТЕМП-4М, полученного при использовании синтетической (1) или натуральной (2) мишени.

ния. Микротвердость полученных покрытий оказалась выше микротвердости титана и кортикальной кости [12]. Значения модуля упругости покрытий находятся в диапазоне 6-14 ГПа, что соизмеримо с модулем упругости кортикальной кости (18 ГПа). Все это свидетельствует в пользу того, что изделия с подобными покрытиями пригодны для применения в качестве имплантатов, заменяющих костные ткани, так как отвечают требованиям, предъявляемым к костным имплантатам.

Результаты измерений толщины покрытий, проведенных профилометрическим методом, приведены на рис. 4. Наблюдается линейный рост толщины покрытия при увеличении количества импульсов МИИП. При данных параметрах облучения скорость осаждения покрытия (т.е. увеличение его толщины за один импульс тока пучка) при использовании синтетической мишени составил 0.65 нм/импульс, а натуральной -4 нм/импульс. Таким образом, мишень из натурального ГАП эродирует более интенсивно, чем керамическая, изготовленная из синтетического ГАП. По всей видимости, данное обстоятельство обусловлено тем, что поверхность натуральной мишени оказалась более пористой и шероховатой по сравнению с синтетической. Этому способствовала более низкая температура спекания натуральной мишени по сравнению со случаем синтетической (известно, что при меньшей температуре спекания получаются более пористые материалы, обладающие избыточной поверхностной энергией [13]). Наличие развитого поверхностного рельефа должно способствовать повышению скорости удаления вещества с поверхности за счет испарения. 
Таблица 2. Физико-механические свойства КФ-покрытий

\begin{tabular}{l|c|c|c|c}
\hline \multicolumn{1}{|l|}{ Подложка/мишень } & $\begin{array}{c}\text { Количество } \\
\text { импульсов МИИП }\end{array}$ & $\begin{array}{c}R_{a} \text {, мкм/класс } \\
\text { шероховатости }\end{array}$ & $\begin{array}{c}\text { Модуль } \\
\text { упругости } E, \text { ГПа }\end{array}$ & $\begin{array}{c}\text { Микротвердость } \\
H, \text { ГПа }\end{array}$ \\
\hline $\begin{array}{l}\text { Тi/синтетический } \\
\text { гидроксиапатит }\end{array}$ & 300 & $0.73 / 11 \mathrm{a}$ & $6.2 \pm 0.3$ & $3.5 \pm 0.4$ \\
\hline $\begin{array}{l}\text { Тi/натуральный } \\
\text { гидроксиапатит }\end{array}$ & 300 & $0.54 / 116$ & $14.5 \pm 1.3$ & $5.0 \pm 1.6$ \\
\hline \multicolumn{2}{c|}{$\mathrm{Ti}$} & $0.01 / 13 \sigma$ & 110 & $\sim 1$ \\
\hline \multicolumn{2}{c|}{ Кортикальная кость } & - & $\sim 18$ & $0.51 \pm 0.01$ \\
\hline
\end{tabular}

Токсикологические испытания местнораздражающего действия и гемолитической активности медицинских изделий (материалов), устанавливающие их безопасность, проведенные в аккредитованном испытательном лабораторном центре ФГУН “Новосибирский НИИ гигиены”, подтверждают, что металлические изделия с биосовместимыми КФ-покрытиями, полученными с использованием МИИП, нетоксичны, апирогенны, не вызывают дегенеративных изменений тканей при имплантации, соответствуют требованиям нормативных документов.

\section{МЕТОДИКА РАСЧЕТОВ И АНАЛИЗ ИХ РЕЗУЛЬТАТОВ}

Для понимания закономерностей происходящих процессов и прогнозирования характеристик осаждения необходимо иметь представление о механизмах удаления вещества из поверхностных слоев мишени под действием МИИП, т.е. ее эрозии. В работах $[8,9]$ показано, что эрозия поверхности твердого тела под действием МИИП с плотностью мощности, превышающей $10^{7} \mathrm{BT} / \mathrm{cm}^{2}$, является следствием радиационного разогрева тонких приповерхностных слоев облучаемой мишени. Вещество удаляется с поверхности конденсированной фазы в результате перехода в пароплазменное состояние. Предложена математическая модель эрозии, предполагающая, что ее доминирующим механизмом под действием импульсных пучков ионов и электронов с начальной энергией 10-1000 кэВ и плотностью мощности $10^{6}-10^{9} \mathrm{BT} / \mathrm{cm}^{2}$ является поверхностное испарение, которое в диапазоне $P \geq 10^{9}-10^{10} \mathrm{~B} / \mathrm{cm}^{2}$ переходит в гидродинамический разлет паров. При облучении ионами в эрозионном потоке должны также присутствовать частицы, выбитые из приповерхностных слоев мишени за счет столкновительного распыления. Однако в исследуемом диапазоне мощности их доля составляет не более $1 \%$ [8].

Интенсивность и энергоэффективность эрозии поверхности мишени и осаждения покрытий определяются параметрами облучения. Ранее, с использованием математического моделирова- ния, были установлены их закономерности применительно к металлическим материалам $[8,9]$. В настоящей статье представлены результаты расчетов для мишеней из ГАП, облучаемых пучками смешанного состава (протоны и ионы углерода в разном соотношении) с начальной энергией частиц $E_{0}=250-500$ кэВ и длительностью импульса тока от нескольких десятков наносекунд до нескольких микросекунд. Указанные параметры МИИП свойственны современным ускорителям ионов, пригодным к эксплуатации в промышленных условиях. Энергоэффективность осаждения оценивалась по поведению коэффициента использования энергии пучка на испарение вещества с поверхности мишени $\left(K_{\mathrm{ev}}\right)$ в зависимости от различных параметров облучения.

Расчеты для ГАП, выполненные с использованием упомянутой выше модели, показывают, что поведение $K_{\mathrm{ev}}$ в зависимости от параметров МИИП имеет вид, аналогичный случаю металлов: наличие максимума при наращивании плотности тока $(J)$ и плотности энергии $(F)$ пучка, рост его значения с увеличением начальной энергии частиц пучка $\left(E_{0}\right)$ и доли протонов в нем, уменьшение $K_{\text {ev }}$ с увеличением длительности импульса тока при фиксированном значении плотности энергии пучка (рис. 5). Из результатов, приведенных на этом рисунке, следует, что при начальной энергии бомбардирующих частиц, равной нескольким сотням килоэлектронвольт, и при субмикросекундной длительности импульсов тока значения $K_{\text {еv }}$ достигают $60 \%$. Увеличение длительности импульсов тока от нескольких десятков наносекунд до нескольких микросекунд при неизменном флуенсе приводит к уменьшению доли энергии пучка, расходуемой на испарение, примерно в два раза.

Наибольшими показателями энергоэффективности эрозии обладают протонные пучки. Но для обеспечения максимальных значений $K_{\mathrm{ev}}$ плотность энергии в импульсе у них должна быть гораздо выше по сравнению с пучками более тяжелых ионов.

Скорость роста покрытия $f_{\text {dep }}$, которая характеризует производительность технологического 


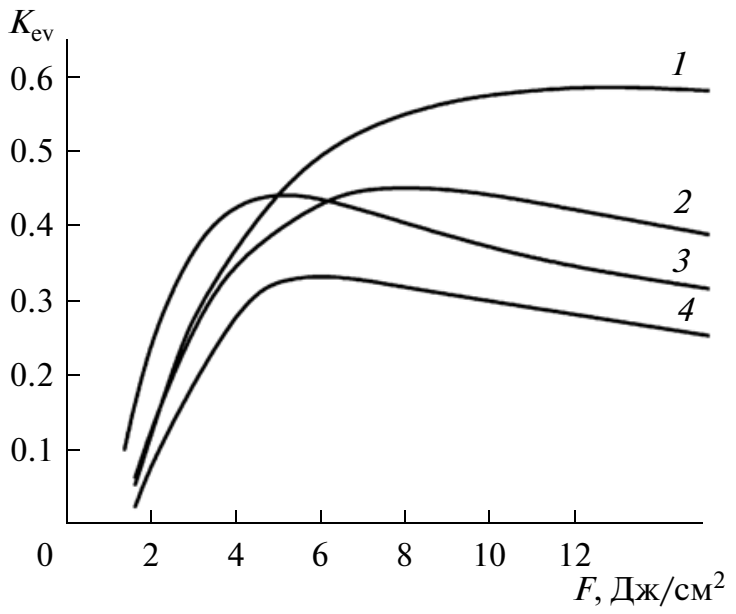

Рис. 5. Зависимость доли энергии пучка, расходуемой на испарение вешества с поверхности мишени из гидроксиапатита $\left(K_{\mathrm{ev}}\right)$, от плотности энергии ионного пучка смешанного состава: $1-\left(30 \% \mathrm{C}^{+}+70 \% \mathrm{H}^{+}\right)$, $E_{0}=250 \mathrm{\kappa эB}, \tau=80 \mathrm{нс} ; 2-\left(70 \% \mathrm{C}^{+}+30 \% \mathrm{H}^{+}\right), E_{0}=$ $=500 \mathrm{K \ni B}, \tau=80 \mathrm{Hc} ; 3-\left(70 \% \mathrm{C}^{+}+30 \% \mathrm{H}^{+}\right), E_{0}=$ $=250 \mathrm{~K} \ni \mathrm{B}, \tau=80 \mathrm{Hc} ; 4-\left(70 \% \mathrm{C}^{+}+30 \% \mathrm{H}^{+}\right), E_{0}=$ $=250 \mathrm{\kappa эB}, \tau=500 \mathrm{Hc}$.

процесса работы ускорителя в частотно-импульсном режиме, равна:

$$
f_{\text {dep }}=Z_{\text {dep }} v,
$$

где $Z_{\mathrm{dep}}-$ темп осаждения или прирост толщины покрытия за один импульс тока пучка, $v$ - частота следования импульсов ускорителя. Линейная зависимость $f_{\text {dep }}$ от $Z_{\text {dep }}$ подтверждается результатами экспериментов на современных ускорителях с покрытиями из различных материалов, в том числе и при осаждении КФ-покрытий (рис. 4).

Таким образом, для расчета производительности технологии осаждения покрытий в частотноимпульсном режиме облучения мощными ионными пучками необходимо научиться определять темп осаждения покрытий.

Предположим, что схема осаждения покрытий из эрозионного материала, образующегося под действием МИИП, на мишень имеет вид, представленный на рис. 1. Как правило, поверхности мишени и подложки параллельны друг другу или находятся под небольшим углом. Площадь сечения пучка обычно составляет десятки квадратных сантиметров. Площадь мишеней равна или несколько больше площади поперечного сечения пучка, что позволяет избежать нежелательного распыления конструкционных элементов диода.

Пусть известна скорость $v$ образования эрозионного материала на поверхности мишени в любой момент времени $t$, которая, к примеру, вычисляется с использованием упомянутой выше модели поверхностного испарения [8]. Предположим, что разлет вещества, испаренного с элементарной площадки $i$ на поверхности мишени, происходит в телесный угол $2 \pi$, а плотность потока испаряемых атомов (молекул) I имеет косинусоидальное распределение по углу разлета $\varphi$, отсчитываемому от нормали к поверхности мишени:

$$
I(\varphi)=I_{0} \cos \varphi,
$$

где $I_{0}$ - плотность потока вещества в направлении нормали к поверхности мишени.

Используя второй закон Ламберта-Кнудсена [14], получаем следуюшую формулу для расчета скорости роста толщины покрытия из вещества, испаряемого с элементарной площадки $i$ на мишени с площадью $d S$ в момент времени $t$ :

$$
V_{\mathrm{dep} i}=\frac{v d S \cos ^{4} \varphi_{i}}{\pi L^{2}}
$$

Здесь $L-$ расстояние между поверхностями мишени и подложки, $\varphi_{i}-$ угол между нормалью к поверхности элементарной $i$-й площадки на мишени и направлением распространения осаждаемого вешества. Тогда толщина покрытия $Z_{\mathrm{dep}}$ на элементе подложки с координатами $(x, y)$, осажденного за один импульс тока, с учетом удаления вешества со всей области испарения на поверхности мишени, имеющей площадь $S_{C}$, может быть вычислена по следующей формуле:

$$
\begin{gathered}
Z_{\mathrm{dep}}(x, y)= \\
=\frac{1}{\rho_{f}} \int_{0}^{t_{\text {end }}} \frac{\mathrm{V}(t)}{\pi} \iint_{S_{c}} \frac{L^{2} d x_{c} d y_{c}}{\left(L^{2}+\left(x-x_{c}\right)^{2}+\left(y-y_{c}\right)^{2}\right)^{2}} d t,
\end{gathered}
$$

где $t_{\text {end }}-$ расчетное время окончания испарения, отсчитываемое от момента начала действия импульса тока на мишень, $\rho_{f}$ - плотность осаждаемой пленки, $V-$ мгновенная скорость испарения в момент времени $t$.

Нами были выполнены расчеты темпа осаждения, интенсивности и энергоэффективности удаления вещества с поверхности гидроксиапатитной мишени в зависимости от различных параметров пучков. Диапазон параметров был выбран исходя из возможностей современных импульсных ионных ускорителей, создаваемых для технологических целей.

На рис. 6 показана зависимость темпа осаждения КФ-покрытий от плотности тока $J$ ионного пучка импульсного ускорителя типа ТЕМП-4М. Здесь и далее имеется в виду максимальная толщина покрытия, которая достигается в точке на поверхности подложки, расположенной напротив центра мишени. На этом рисунке сплошные линии - результаты расчетов по описанной выше методике, точки соответствуют результатам экспериментов, полученным при аналогичных параметрах облучения. Довольно хорошее совпадение расчетных и экспериментальных результатов сви- 


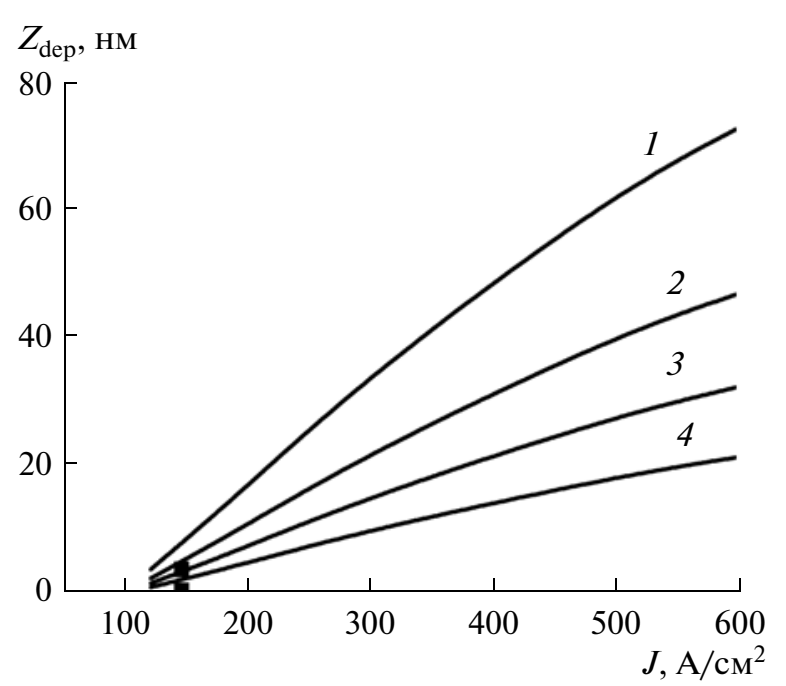

Рис. 6. Зависимость темпа осаждения КФ-покрытия $\left(Z_{\mathrm{dep}}\right)$ от плотности тока ионного пучка смешанного состава $\left(70 \% \mathrm{C}^{+}+30 \% \mathrm{H}^{+}\right)$с начальной энергией частиц 250 кэВ и длительностью импульса 80 нс при разном расстоянии $L$ между мишенью и подложкой ( $1-5$ см, $2-6.5 \mathrm{~cm}, 3-8 \mathrm{~cm}, 4-10$ см): сплошные линии - результаты расчетов, точки - данные экспериментов при облучении мишени из натурального (верхняя точка) и синтетического (нижняя точка) гидроксиапатита.

детельствует о том, что модельные представления о механизмах эрозии и методика расчета темпа осаждения являются пригодными для прогнозирования производительности осаждения КФ-покрытий при использовании мощных импульсных ионных пучков.

Порог по плотности тока получения КФ-покрытий при использовании подобных пучков лежит в диапазоне 100-300 А/см² в зависимости от начальной энергии частиц и состава пучка. При частоте следования импульсов на уровне 0.1-1.0 Гц, что соответствует возможностям современных частотно-импульсных ускорителей, производительность осаждения КФ-покрытий составляет 0.1$100 \mathrm{HM} / \mathrm{c}$.

На рис. 7 показано изменение темпа осаждения КФ-покрытий в зависимости от плотности энергии $F$ ионного пучка смешанного состава с различным соотношением протонов и ионов углерода, а также при разных значениях начальной энергии частиц $E_{0}$. При одинаковых значениях $F$ и идентичном составе пучка наблюдается небольшое расхождение в значениях темпа осаждения, соответствующих разным значениям $E_{0}$. Причем, если при невысоких $F$ значения $Z_{\text {dep }}$ выше при меньших $E_{0}$, то по мере наращивания плотности энергии ситуация изменяется: чем выше начальная энергия частиц в пучке, тем больше темп осаждения. Состав пучка также оказывает влияние на

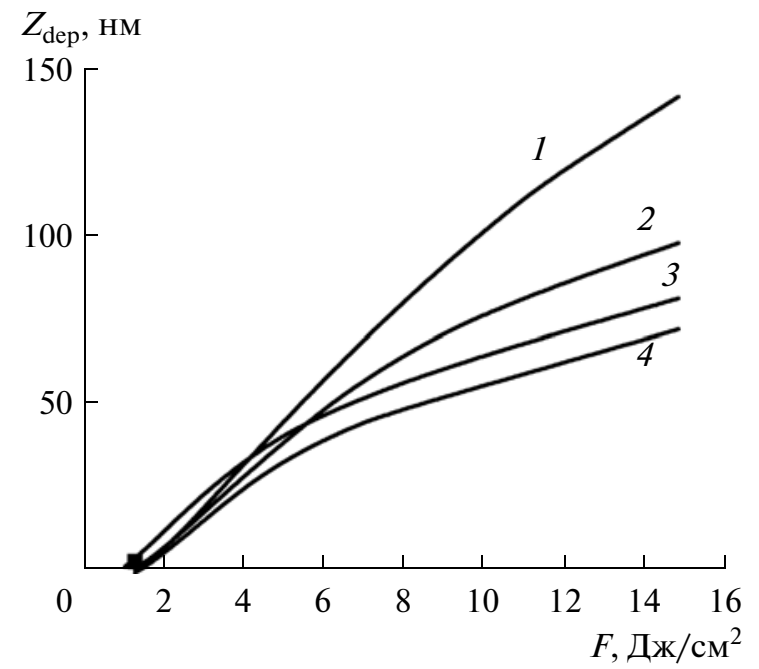

Рис. 7. Зависимость темпа осаждения КФ-покрытия от плотности энергии ионного пучка смешанного состава с разными длительностью импульса $\tau$ и начальной энергией частиц $E_{0}$; пучок падает на мишень под углом к нормали ее поверхности $45^{\circ}$, радиус следа пучка $r$ на мишени -2.5 см, расстояние между параллельно расположенными мишенью и подложкой $6.5 \mathrm{cм}: 1-\left(30 \% \mathrm{C}^{+}+70 \% \mathrm{H}^{+}\right), E_{0}=250 \mathrm{\kappa эB}, \tau=80 \mathrm{Hc}$; $2-\left(70 \% \mathrm{C}^{+}+30 \% \mathrm{H}^{+}\right), E_{0}=500 \mathrm{кэ} \mathrm{B}, \tau=80 \mathrm{нс} ; 3-$ $\left(70 \% \mathrm{C}^{+}+30 \% \mathrm{H}^{+}\right), E_{0}=250 \mathrm{\kappa эB}, \tau=80 \mathrm{Hc} ; 4-$ $\left(70 \% \mathrm{C}^{+}+30 \% \mathrm{H}^{+}\right), E_{0}=250 \mathrm{кэB}, \tau=500 \mathrm{Hс}$.

поведение $Z_{\mathrm{dep}}(F)$ : чем больше протонов в пучке, тем выше темп осаждения при одинаковой плотности энергии пучка. Увеличение длительности импульса тока при неизменном флуенсе приводит к некоторому падению темпа осаждения за счет увеличения доли энергии пучка, распространяющейся из области торможения частиц в глубину мишени за счет теплопроводности.

Из рис. 7 следует, что всем зависимостям $Z_{\text {dep }}(F)$ свойственен быстрый рост темпа осаждения с увеличением $F$ при небольших значениях плотности энергии пучка, а затем - выход на насыщение по мере наращивания $F$. Эта закономерность обусловлена возрастанием потерь энергии пучка в парах и, следовательно, понижением интенсивности образования эрозионного материала.

\section{ЗАКЛЮЧЕНИЕ}

Анализ возможностей современных субмикросекундных ионных ускорителей типа ТЕМП4М показывает, что принципиально они пригодны для осаждения кальций-фосфатных покрытий на металлическую основу костных имплантатов нового поколения. Получаемые с их использованием кальций-фосфатные покрытия содержат в своем составе необходимые химические элементы и удовлетворяют биомедицинским требованиям по микротвердости и значению модуля Юнга. Они полностью закрывают подложку и имеют хо- 
рошую адгезию к материалу основы. Технология изготовления гидроксиапатитной мишени влияет на свойства кальций-фосфатных покрытий и темп их осаждения. Пористые и шероховатые мишени способны обеспечить более высокую скорость формирования покрытий. Хорошее согласие результатов экспериментов с расчетами темпа осаждения кальций-фосфатных покрытий свидетельствует в пользу того, что основным механизмом образования осаждаемого материала является испарение атомов и молекул из поверхностных слоев облучаемой мишени. С помощью численного моделирования получены закономерности производительности и энергоэффективности осаждения в зависимости от параметров пучков. Расчеты показали, что использованные в экспериментах параметры пучков не являются оптимальными. Для повышения производительности технологии и ее энергоэффективности желательно генерировать пучки с преимущественным содержанием протонов и с плотностью энергии на уровне 5-10 Дж/см² (при условии, что осаждаемые покрытия будут удовлетворять биомедицинским требованиям).

Работа частично выполнялась в рамках государственного задания "Наука" и при поддержке Федеральной целевой программы “Исследования и разработки по приоритетным направлениям развития научно-технологического комплекса России на 2007-2013 годы” (ГК 14.512.11.0012), гранта РФФИ № 11-08-98032-р_сибирь_а, Госзадания НИР № 0.328.2012 (проекТ № 7.1084.2011).

\section{СПИСОК ЛИТЕРАТУРЫ}

1. Isakov I.F., Remnev G.E., Zakutaev A.N. // Proc. $9^{\text {th }}$ Int. Conf. High-Power Particle Beams. NTIS, Springfield, 1992. P. 1966.
2. Renk T.J., Provencio P.P., Prasad S.V. et al. // Proc. IEEE. 2004. V. 92. № 7. P. 1057.

3. Yatsui K., Sonegawa T., Ohtomo K., Jiang W. // Mater. Chem. Phys. 1998. V. 54. P. 219.

4. Струи В.К., Петров А.В., Матвиенко В.М. и др. // Поверхность. Рентген., синхротр. и нейтрон. исслед. 2011. № 5. C. 97. (Struts V.K., Petrov A.V., Matvienko V.M. et al. // J. Surf. Investigation. X-ray, Synchrotron and Neutron Techniques. 2011. V. 5. № 3. P. 497).

5. Твердохлебов С.И., Ремнёв Г.Е., Пушкарёв А.И. и др. // Современные керамические материалы и их применение. Тр. научно-практ. конф. Новосибирск: Изд-во “Сибпринт", 2010. С. 111.

6. Saltymakov M.S., Tverdokhlebov S.I., Pushkarev A.I., Volokitina T.L. // Proc. $18^{\text {th }}$ Int. Conf. High-Power Particle Beams. ICC Jeju, Korea, 2010. P. 236.

7. Пичугин В.Ф., Ешенко Е.В., Сурменев Р.А. // Поверхность. Рентген., синхротр. и нейтрон. исслед. 2007. № 11. C. 67. (Pichugin V.F., Eshenko E.V., Surmenev R.A. et al. // J. Surf. Investigation. X-ray, Synchrotron and Neutron Techniques. 2007. V. 1. № 6. P. 679).

8. Bleykher G.A., Krivobokov V.P. // J. Eng. Thermophys. 2008. V. 17. № 1. P. 24.

9. Блейхер Г.А., Кривобоков В.П. // Изв. вузов. Порошковая металлургия. 2008. № 1. С. 23.

10. Исакова Ю.И., Пушкарев А.И., Тарбоков В.А. // Изв. Томск. политехн. ун-та. 2010. Т. 316. № 2. С. 76.

11. Чайкина М.В. Механохимия природных и синтетических апатитов. Новосибирск: Изд-во СО РАН, 2002. $250 \mathrm{c}$

12. $L i P$. In vitro and in vivo Calcium Phosphate Induction on Gel Oxide. PhD Thesis. Leiden, 1993. 159 p.

13. Стрелов К.К. Теоретические основы технологии огнеупорных материалов. М.: Металлургия, 1985. $480 \mathrm{c}$.

14. Технология тонких пленок: Справочник. Т. 1. / Ред. Майссел Л., Глэнг Р. М.: Сов. радио, 1977. 664 с.

\title{
The Influence of the Hydroxyapatite Target Irradiation by Pulsed Powerful Ion Beams on the Properties of Formed Calcium-Phosphate Coatings
}

\author{
G. A. Bleykher, T. L. Volokitina, S. I. Tverdokhlebov
}

\begin{abstract}
The biocompatible calcium-phosphate coatings were deposited on titanium and silicon substrates from the erosion products generated by means of irradiation of the hydroxyapatite (synthetic and natural) targets by pulsed powerful ion beams of the TEMP-4M accelerator. Their physical and mechanical properties were investigated. The calculation method to predict the rate and the efficiency of coating deposition using pulsed ion beams was proposed. These characteristics were analyzed in relation with the formation of calcium-phosphate coatings.
\end{abstract}

